\title{
TREATMENT OF TUBERCULOSIS OF THE SPINE
}

\section{BY}

\author{
M. C. WILKINSON, M.B., B.S., F.R.C.S. \\ Orthopaedic Surgeon, Black Notley Hospital, \\ Braintree, Essex
}

The decline in the incidence of bone and joint tuberculosis in this country and in many others should not lead us into the error of thinking that this disease is no longer a problem of major importance, because there are large areas of the world where it is still one of the chief causes of death and crippling. Even in this country the figures are by no means negligible. In the four years 1955-8 the annual admissions to Black Notley Hospital of cases of tuberculosis of the spine of fairly recent origin were $40,32,26$, and 20 respectively. During the same period the annual admissions of cases of old-standing spinal disease in need of further treatment were $9,9,13$, and 13 . The utmost that can be achieved by modern treatment is necessary for these patients. Up-to-date therapy should be combined with the old techniques which have been proved by experience and which are too valuable to be discarded. Constitutional treatment and skilled splintage are still essential to produce the best and quickest results.

In addition to constitutional treatment, posterior fusion has been a popular method of internal fixation of the spine, but any benefit that this produces must be an indirect one, and surgeons have never denied that the removal of sequestra and the drainage of abscesses is the method of choice in dealing with inflammatory diseases of bone. Unfortunately, radical surgical ureatment of tuberculous osteomyelitis was risky until the introduction of antibiotics, as miliary tuberculosis or tuberculous meningitis might be precipitated by operation, with fatal results. An important investigation which emphasized the need for the direct treatment of the paravertebral abscess or granuloma was that of Swett, Bennett, and Street (1940). They published the results of the treatment of 350 patients suffering from spinal tuberculosis and came to the conclusion that the dominant feature in the healing of the disease lay in the "occurrence, behaviour, and disposal" of the abscess, and that it would be good surgical practice to undertake early aseptic evacuation of the abscess.

As the result of favourable experience of the direct operative treatment of tuberculous lesions in peripheral joints I had come to a similar conclusion, and in 1942 Sir Heneage Ogilvie operated with me on a child with gross and advancing spinal disease, it being thought worth while to take the risk of dissemination. The abscess was drained by the costotransversectomy route. The operation did not save the child's life, and it was not until the introduction of streptomycin in 1948 that this work was resumed.

\section{Results Before Use of Antibiotics}

Before considering the results of treatment of the spinal lesion by direct surgery, it will be of value to recall the degree of success obtainable before antibiotics became available. Table I shows the follow-up results in 131 out of a series of 340 patients treated at Black Notley during the years 1931-47. It will be seen that in 40 out of 51 patients treated for disease in the lumbar spine the result was good. In contrast, only 37 out of 75 patients treated for disease in the mid and lower thoracic and thoraco-lumbar regions got a satisfactory result. It should be noted that this table includes only patients who had a recent follow-up record, and does not include 209 whose records were incomplete or who had died. The inadequacy of constitutional treatment for a large number of patients with disease of the mid and lower thoracic spine, shown in Table I, is confirmed from the publications of such workers as Butler (1935), Dobson (1951), and Griffiths, Seddon, and Roaf (1956), all of whom reported that the maximum incidence of paraplegia followed disease in the mid and

TABLE I.-Follow-up Results of 131 out of 340 Patients, Treated During 1931-47 for Tuberculosis of Spine Without Antibiotics or Operation

\begin{tabular}{|c|c|c|c|c|c|c|}
\hline \multirow{2}{*}{$\begin{array}{l}\text { Site of } \\
\text { Lesion }\end{array}$} & \multicolumn{3}{|c|}{ Stable or Bony Ankylosis } & \multicolumn{3}{|c|}{ Unsound Ankylosis } \\
\hline & $\begin{array}{l}<15 \\
\text { Years }\end{array}$ & $\begin{array}{l}15+ \\
\text { Years }\end{array}$ & Total & $\begin{array}{l}<15 \\
\text { Years }\end{array}$ & $\begin{array}{l}15+ \\
\text { Years }\end{array}$ & Total \\
\hline \multirow{4}{*}{$\begin{array}{l}\text { Lumbo-sacral } . \\
\text { Lumbar } \\
\text { Thoraco-lumbar } \\
\text { Lower and mid- } \\
\text { thoracic mo } \\
\text { Upper thoracic .. } \\
\text { Cervical .. }\end{array}$} & $\begin{array}{r}1 \\
12 \\
3\end{array}$ & $\begin{array}{r}3 \\
24 \\
14\end{array}$ & $\begin{array}{l}4 \\
36 \\
17\end{array}$ & $\begin{array}{l}\overline{3} \\
5\end{array}$ & $\begin{array}{l}1 \\
7 \\
5\end{array}$ & $\begin{array}{l}1 \\
10 \\
10\end{array}$ \\
\hline & $\begin{array}{l}7 \\
1\end{array}$ & 13 & $\begin{array}{r}20 \\
1\end{array}$ & $\begin{array}{r}12 \\
1\end{array}$ & $\underline{16}$ & $\begin{array}{r}28 \\
1\end{array}$ \\
\hline & i. & 1 & & i & - & \\
\hline & 25 & 55 & 80 & 22 & 29 & 51 \\
\hline
\end{tabular}

lower thoracic vertebrae. This area is also associated with the development of gross deformity, especially in young children. Therefore it seemed clear, when antibiotics became available, that the main target of direct operation should be the mid and lower thoracic areas.

In 1948 I operated on two men who had tuberculosis of the thoracic spine, and in 1949 on two children with thoracic vertebral disease. My colleague, Mr. Ronald Reid, also operated in 1949 on a woman with lumbar vertebral disease. These patients were given only minimal streptomycin cover-namely, a small dose of the antibiotic twice a day for three weeks. Nevertheless, they suffered no ill effects and the results were most encouraging. Among the lessons learnt from these early operations were that progressive bone destruction could be stopped by operative intervention, and that to ensure a stable spine at the end of treatment the operation must be done before gross vertebral destruction occurs, especially in children, in whom destruction of tuberculous bone may be rapid. A considerable improvement in the patient's general condition was also noted after operation, and there was a tendency for associated lesions, such as pulmonary disease, to heal.

\section{Present Series}

During the period 1948 to 1958 inclusive, 138 operations were performed on 128 patients. In most instances antibiotic cover was given for 14 to 18 weeks. Provided that no bone destruction is occurring, an interval of three to four months is allowed to elapse before operation in the case of adults; in children the interval is shorter. Operation then becomes easier and safer because inflammatory hyperaemia is less. Experience has shown that a paravertebral abscess in a child's spine may resolve as the result of antibiotic treatment, but the process is uncertain and may be incomplete, while the drainage of such an abscess leads to rapid and complete healing. The vertebrae of young children are small and the paravertebral abscess is the major factor to be dealt with. In adults, on the other 
hand, drainage of the abscess, though necessary, is insufficient and curettage of the intravertebral granuloma is also required; sometimes the side of the vertebral body has to be removed to obtain access to the interior. Adult patients have been kept in their plaster beds for four months after operation, children for longer.

Tables II, III, and IV give particulars of the patients treated by direct operation on the spinal lesion. All patients operated on for secondary septic infection of

TABle II.-Number of Patients Treated for Tuberculosis of Spine by Direct Operation on Lesion and Number of Operations Performed

No of patients discharged 1948-58, inclusive ", direct operations performed on these patients ,. patients with recenı follow-up Patients without recent follow-up Operative mortality rate

* Two died (one of non-specific pneumonia three years af discharge and one of tuberculous meningits discharge) and one emigrated.

TABLE III.-State of Lesion on Follow-up of 128 Patients with 130 Spinal Lesions Treated by Direct Operation. Eight Patients Had Two Operations on Initial Lesions and Two Had Operations on Two Spinal Lesions

\begin{tabular}{|c|c|c|c|}
\hline $\begin{array}{l}\text { Duration of } \\
\text { Follow-up }\end{array}$ & $\begin{array}{c}\text { Bony } \\
\text { Ankylosis }\end{array}$ & $\begin{array}{c}\text { Stable Fibrous } \\
\text { Ankylosis }\end{array}$ & $\begin{array}{c}\text { Unstable Fibrous } \\
\text { Ankylosis }\end{array}$ \\
\hline 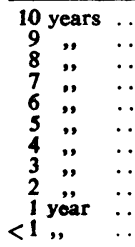 & $\begin{array}{r}2 \\
1 \\
4 \\
6 \\
7 \\
23 \\
12 \\
9 \\
8 \\
7 \\
3\end{array}$ & $\begin{array}{l}3 \\
3 \\
2 \\
5 \\
6 \\
4 \\
4 \\
7 \\
6\end{array}$ & $\begin{array}{l}1 \\
1 \\
1 \\
1 \\
1 \\
2 \\
1\end{array}$ \\
\hline Total & 82 & 40 & 8 \\
\hline
\end{tabular}

TABLE IV.-Follow-up Results of 128 Patients with 130 Lesions Treated by Direct Operation, Grouped According to Situation of Lesion

\begin{tabular}{|c|c|c|c|}
\hline Area of Disease & & $\begin{array}{l}\text { Sound Healing with } \\
\text { Stahle Ankvlosis, } \\
\text { Bony or Fibrous }\end{array}$ & $\begin{array}{l}\text { Unstable } \\
\text { Ankylosis }\end{array}$ \\
\hline $\begin{array}{l}\text { Lumbo-sacral } \\
\text { Lumbar } \quad \ldots \\
\text { Thoraco-lumbar }\end{array}$ & $\begin{array}{l}\cdots \\
\cdots \\
\cdots \\
\cdots\end{array}$ & $\begin{array}{r}31 \\
6 \\
83\end{array}$ & $\begin{array}{l}3 \\
2 \\
5\end{array}$ \\
\hline Total & . & 120 & 10 \\
\hline
\end{tabular}

the spine or for Pott's paraplegia have been excluded from this series. The operative mortality was nil (Table II). The most important operative complication, which has been encountered twice, was tension pneumothorax, due to puncturing the pleura, which may be softened and adherent. Great care is required, therefore, in getting out the rib heads ; this may be difficult, as they may have developed an ankylosis to the vertebral bodies. A frequent sequel to the operation is a mild pleurisy or pleural effusion. When applying the dressing I make a practice of strapping the affected side a little. The patients have stood the operation well. For successful and safe operating two things are essential: first, a high degree of anaesthetic skill, because, if the patient gets anoxic, oozing occurs, impairing vision of the operative field; and, secondly, a high standard of bone radiography, because the definition of the abscess and of cavities and sequestra may be difficult even with good radiography. Quite marked cavitation and sequestration may be present without $x$-ray evidence, and it is also possible to operate for an apparent cavity and to find that it is not there.
The results shown in the tables were obtained in spite of the fact that many of the patients, especially in the first years, were selected for operation on account of severe disease for which orthodox methods of treatment had failed. The eight patients who are reported to have recovered with unstable fibrous ankylosis (Table III) include some who had extensive vertebral destruction but who improved to the extent that they were leading normal and useful lives. Concerning those classified as having bony or stable fibrous ankylosis, the distinction is sometimes invidious and difficult to determine. Under the heading "stable fibrous ankylosis" are included a type of result not often seen formerly-namely, re-formation of the vertebral bodies and considerable restitution of the intervertebral joint space.

These tables also show that the majority of patients treated by direct operation on the lesion had disease of the mid and lower thoracic and thoraco-lumbar portions of the spine-that is, the areas where poor results were formerly frequent. In spite of the unfavourable site of the lesions, most of these patients got an excellent result. They were selected for operation because it was felt that otherwise their prognosis was poor. They should be compared with another group of patients, shown in Table $\mathrm{V}$, most of whom had disease in the lumbar region, for whom the prognosis was considered to be satisfactory without operation. There were 105 of these patients, treated over the same period of time as the operated patients. It is seen that the patients with disease in the lumbar region, with the exception of the 34 patients (Table IV) who were operated on, did well with conservative treatment and antibiotics only. The patients with disease in the thoracic portion of the spine (Table V), although they had been spared operation, as it was thought it was not necessary, fared less well than the more severe group who were operated on.

Table VI shows the number of patients who required readmission for further treatment. This was by no means a negligible proportion, and it follows that the treatment of spinal tuberculosis is still fraught with problems and difficulties. On the other hand, many of these patients had very severe disease, operated on in the early days as a last resort. Two of the patients in the series were readmitted with Pott's paraplegia-one

TABLE V.-Results of Treatment of 105 Patients. Most of Whom Had Disease Thought to be of Such a Nature that it Would Recover Without Operation. Follow-up Results of Many of These Patients are Incomplete

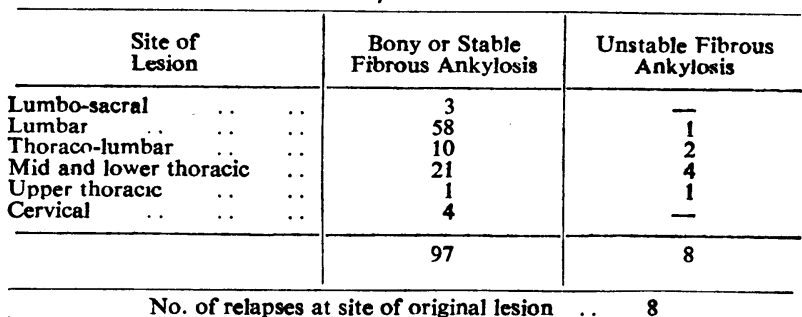

$$
\begin{array}{llll}
\text { No. of relapses at site of original lesion } & \ldots & 8 \\
\text {, , , another site or organ } & \ldots & 3
\end{array}
$$

TABLE VI.-Classification According to Types of Reactivation of 21 Patients Readmitted for Further Treatment

Readmitted for operation on fresh lesion in spine "̈ "̈ further operation on lesion treated previously by oneräion

Readmitted for disease elsewhere, renal or skeletal $\quad \ldots \quad \ldots$ Readmission for posterior spinal fusion Readmitted for additional constitutional and antibiotic

$\begin{array}{lllll}\text { treatment } & & & \end{array}$

All these patients, except one who died and one still under treatment, have made a full recovery. 
a child who had been treated by direct operation late in the disease, and the other a West Indian with extensive disease extending over nine vertebral bodies. These 21 patients have since readmission recovered and maintained their recovery with the exception of the West Indian, who is completing his treatment. Only one patient in the operative series has died of tuberculosisa woman who was reported to have developed tuberculous meningitis three years after her discharge from Black Notley. Another patient died of non-specific pneumonia three years after discharge. The mortality rate of less than $2 \%$ for this disease on follow-up compares very favourably with the mortality rate before the introduction of antibiotics, which for most centres on five-year follow-up was approximately $30 \%$.

The results obtained by constitutional therapy, antibiotics, and direct operation on the lesion are very reassuring, and patients have been allowed to return to full activities soon after leaving hospital. Children have been permitted to return to ordinary school and to take part in games within a short time. A spinal brace is worn by some patients on discharge, but seldom for longer than four months. A summary of the occupations to which operated patients have returned is shown in Table VII.

TABLE VII.-Particulars Concerning Employment of 120 Patients Treated by Direct Operation for Vertebral Tuberculosis

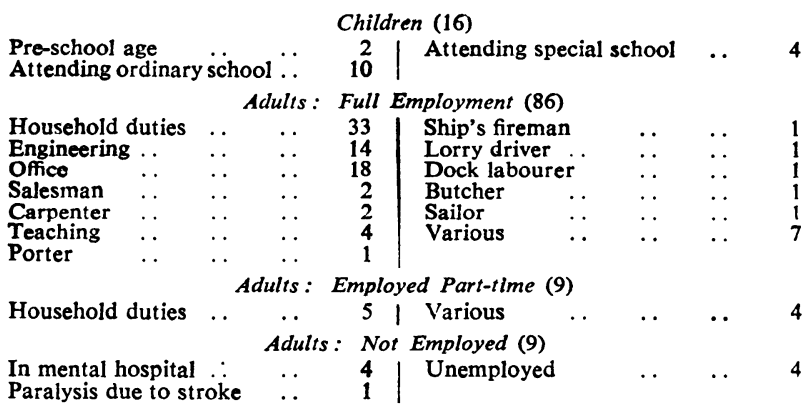

The average duration of treatment of the patients treated by direct operation was 9.7 months. These figures show that, by the direct operative treatment of tuberculosis of the spine, good and relatively speedy results can be obtained, with the early return of the patient to full employment. With a two-rib costotransversectomy approach the operation is safe if done with precision and deliberation, with the aid of preliminary constitutional and antibiotic therapy, and with a sufficient antibiotic cover. By this route an adequate access can be obtained to two or three vertebral bodies. For more extensive lesions the transpleural route advocated by Hodgson and Stock (1956) may well be preferable if facilities are available for its safe performance. After the debridement of the vertebral lesion, whatever may be the route of access, the vertebral defect may be reinforced with cancellous bone chips taken from the posterior part of the iliac crest, though in the smaller lesions this procedure is not strictly necessary. If the transpleural approach has been used, an anterior strut graft may be inserted by the technique of Hodgson and Stock, and by preventing the onset of deformity this may be of great benefit to patients with an extensive lesion.

\section{Summary}

The results are given of a combination of constitutional treatment, antibiotics, and direct operation for the treatment of certain patients suffering from tuberculosis of the spine. The selection of suitable cases for this form of operative treatment depends, inter alia, on the situation of the vertebral lesion. Previous experience had shown that the prognosis was worse for tuberculosis of the lower thoracic spine than for disease in the lumbar region. Experience with the direct operation has been most encouraging; the recovery rate is more rapid and certain, and the return of function is assured in most patients. On the other hand, patients with disease in the lumbar region not operated on also did well. Tuberculosis of the spine can now be rendered a curable disease with a good prognosis.

I am grateful to Sir Heneage Ogilvie, Mr. S. L. Higgs, and Mr. Ronald Reid for their help in this work. I am indebted to Dr. Jack Dixon, whose skilled anaesthesia has made the operation safe, and to Dr. Franklin Wood, whose early interest in the possibilities of bone tomography contributed materially to the success of the operations. I also thank the Editor of the Annals of the Royal College of Surgeons of England for permission to use Table I.

\section{REPERENCES}

Butler, R. W. (1935). Brit. J. Surg., 22, 738

Dobson, J. (1951). J. Bone Jt Surg., 33B, 517

Griffiths, D. Ll., Seddon, H. J., and Roaf, R. (1956). Pott's Paraplegia. Oxford Univ. Press, London.

Hodgson, A. R., and Stock, F. E. (1956). Brit. J. Surg., 44, 266.

Swett, P. P., Bennett, G. E., and Street, D. M. (1940). J. Bone Jt Surg., 22, 878

\section{STANLEYVILLE I AND II TWO NEW VARIANTS OF ADULT HAEMOGLOBIN} BY PAULETTE DHERTE

Belgian Congo Provincial Medical Laboratory, Stanleyville, Belgian Congo

\section{J. VANDEPITTE, M.D.}

Department of Bacteriology, Lovanium University, Leopoldville, Belgian Congo

J. A. M. AGER, M.B., B.S.

Department of Pathology, St. Thomas's Hospital, London

AND

H. LEHMANN, M.D., Sc.D., M.R.C.P., F.R.I.C.

Department of Pathology, St. Bartholomew's Hospital. London

In the course of a survey of haemoglobin types seen in the antenatal clinic at Stanleyville, a number of women were discovered whose red cells did not sickle but whose haemoglobin behaved on electrophoresis and chromatography like a mixture of haemoglobins $A$ and $S$-that is, the abnormal haemoglobin was haemoglobin D. This was confirmed by solubility tests after Itano (1953) where the solubility of the haemoglobin was that of AD samples and not of AS samples.

In addition two abnormal haemoglobins were found to resemble haemoglobin $\mathrm{D}$ in some respects but to differ in others.

\begin{tabular}{|c|c|c|}
\hline \multicolumn{3}{|c|}{ Techniques Employed } \\
\hline Sickle-cell test & . & Daland and Castle (1948) \\
\hline \multirow{2}{*}{\multicolumn{2}{|c|}{ Paper electrophoresis }} & $\begin{array}{l}\text { Hanging-strip method according to } \\
\text { Lehmann and Smith (1954) }\end{array}$ \\
\hline & & $\begin{array}{l}\text { Alkaline: barbitone buffer, pH } 8.6 \\
\text { Acid: phosphate buffer, pH } 6.5\end{array}$ \\
\hline Alkali denaturation & $\cdots$ & $\begin{array}{l}\text { 1-minute test of Singer, Chernoff, and } \\
\text { Singer (1951) }\end{array}$ \\
\hline Cold denaturation & - & Rigas, Koler, and Osgood (1956) \\
\hline Solubility $\quad \ldots$ & . & Itano (1953) \\
\hline Chromatography & & Huisman and Prins (1955) \\
\hline
\end{tabular}

